\title{
Mid-term effect of Roux-en-Y gastric bypass on type 2 diabetes mellitus: a retrospective single surgeon observational study with focus on anti-diabetic medication
}

Efeito do bypass gastric em Y de Roux no diabetes tipo 2: estudo observacional retrospectivo de um único cirurgião com foco em medicação antidiabética

Ben Gys, MD, Filip Haenen, MD, Tobie Gys, MD, Thierry Lafullarde, MD

Study performed at Department of surgery, AZ Sint Dimpna, J-.B. Stessensstraat 2, B-2440 Geel, Belgium Financial support: none.

Conflict of interest: None.

Correspondence address: Ben GYS, J-.B. Stessensstraat 2 - B-2440 Geel, Belgium ben.gys@gmail.com

Submitted: October 20, 2016. Accepted, after review: January 3, 2017.

\section{ABSTRACT}

Background/purpose: Few studies evaluating the mid-term outcome of type 2 diabetes mellitus (t2DM) after Roux-en-Y Gastric Bypass (RYGB) are available at this time. The aim of this study is to assess mid-term impact of RYGB on t2DM regarding the need for anti-diabetic medication, biochemical response and associated weight loss. Methods: Retrospective analysis of prospectively collected data was performed for patients suffering from t2DM who underwent RYGB between 1/1/2000 and 1/1/2015. Patients were divided into 2 groups according to the preoperative need for insulin. Study parameters included Body Mass Index (BMI), \%Excess Weight Loss (\%EWL), Hemoglobin A1c (HbA1c) and fasting glucose at 1, 3,6 and 10-year intervals after surgery. Results: 140 patients (97 women, 43 men) were included. Mean preoperative BMI was $42.8 \mathrm{~kg} / \mathrm{m}^{2}$ (range 35.0 - 75.0). Mean duration of t2DM before RYGB was 5,7 years (range $0,2-30,1$ ). Preoperative need for anti-diabetic medication was seen in 102 patients $(72,8 \%)$ of which $49(48,0 \%)$ were insulin-dependent (ID-group). Mean postoperative follow-up was 5,9 years (range 0,1 $-14,5$ ). Remission of t2DM (fasting glucose $<126 \mathrm{mg} / \mathrm{dl}$ and a $\mathrm{HbA} 1 \mathrm{c}<6.5 \%$ without the need of anti-diabetic medication for at least 6 months) was present in both groups: $46,7 \%, 48,1 \%, 45,0 \%, 50,0 \%$ (ID-group) and $59,1 \%, 62,2 \%, 53,3 \%, 33,3 \%$ (insulinindependent patients) at respectively $1,3,6$ and 10-years followup. No significant correlation was proven between remission and \%EWL. Conclusions: Bariatric surgery is useful in the mid-term management of uncontrolled t2DM.

Key words: Obesity. Diabetes mellitus. Bariatric surgery. 


\section{RESUMO}

Objetivo: Poucos estudos que avaliam o resultado a médio prazo do diabetes mellitus tipo 2 (t2DM) após o bypass gástrico de Roux-en-Y (RYGB) estão disponíveis neste momento. O objetivo deste estudo é avaliar o impacto a médio prazo do RYGB no t2DM quanto à necessidade de medicação antidiabética, resposta bioquímica e perda de peso associada. Métodos: Realizou-se análise retrospectiva de dados coletados prospectivamente para pacientes com DM2 submetidos a RYGB entre 1/1/2000 e 1/1/2015. Os pacientes foram divididos em 2 grupos de acordo com a necessidade pré-operatória de insulina. Os parâmetros do estudo incluíram Índice de Massa Corporal (IMC),\% de Perda de Peso em Excesso (\% PPE), Hemoglobina A1c (HbA1c) e glicemia de jejum em intervalos de 1, 3, 6 e 10 anos após a cirurgia. Resultados: Foram incluídos 140 pacientes (97 mulheres, 43 homens). O IMC pré-operatório médio foi de $42,8 \mathrm{~kg} / \mathrm{m}^{2}$ (intervalo 35,0 - 75,0). A duração média do t2DM antes do RYGB foi de 5,7 anos (intervalo 0,2 - 30,1). A necessidade pré-operatória de medicação antidiabética foi observada em 102 pacientes $(72,8 \%)$ dos quais 49 $(48,0 \%)$ eram insulinodependentes (grupo ID). O seguimento pós-operatório médio foi de 5,9 anos (variação de 0,1 a 14,5). A redução do t2DM (glicemia de jejum $<126 \mathrm{mg}$ / dl e HbA1c <6,5\% sem necessidade de medicação antidiabética por pelo menos 6 meses) esteve presente nos dois grupos: $46,7 \%, 48,1 \%, 45,0 \%, 50,0 \%$ (grupo ID) e $59,1 \%, 62,2 \%, 53,3 \%, 33,3 \%$ (pacientes independentes de insulina), respectivamente, com seguimento de 1, 3, 6 e 10 anos. Nenhuma correlação significativa foi comprovada entre remissão e \% perda de peso. Conclusão: A cirurgia bariátrica é útil no manejo de médio prazo do t2DM não controlado.

Descritores: Obesidade. Diabetes mellitus. Cirurgia bariátrica.

\section{INTRODUCTION}

With a worldwide prevalence of $9 \%$ among adults, type 2 diabetes (t2DM) is found to be a major pandemic with an estimate of 1.5 million deaths in $2012^{12}$. The disease is characterized by hyperglycemia caused by insulin resistance. It is known that weight loss can have a substantial positive effect. Maintenance of a stable weight can however be a serious endeavor in morbidly obese patients. It was stated in 2013 that diabetes at least doubles a person's mortality ${ }^{3}$.

Roux-en-Y gastric bypass (RYGB) is a popular bariatric intervention which was initially developed by Dr. Edward Mason in the 1960's. It has shown excellent mid-term weight loss results by combining food restriction (by the creation of a small stomach 
Mid-term effect of Roux-en-Y gastric bypass on type 2 diabetes mellitus: a retrospective single surgeon observational study with focus on anti-diabetic medication

Gys, B; et al

pouch) and relative malabsorption (intestinal bypass). A mid-term significant amelioration or even resolution of comorbidities is frequently seen in patients. Few studies evaluating the mid-term outcome of t2DM after RYGB are available at this time.

The aim of this study is to retrospectively analyze mid-term effects of RYGB on t2DM regarding the need for anti-diabetic medication (insulin dependency), alteration of biochemical parameters and associated weight loss in a single surgeon setting.

\section{METHODS}

Retrospective analysis of prospectively collected data was performed for patients suffering from t2DM (following current WHO criteria4: fasting glycaemia $\geq$ $126 \mathrm{mg} / \mathrm{dl}$ and $/$ or 2-h plasma glucose test $\geq 200 \mathrm{mg} / \mathrm{dl}$ ) undergoing RYGB between the $1 / 1 / 2000$ and $1 / 1 / 2015$. All surgical interventions were performed by a single surgeon (TL) after obtainment of an informed consent and standard preoperative multidisciplinary consideration (consisting of the operating surgeon, a cardiologist, endocrinologist, dietician and psychologist). Patients undergoing standard RYGB (including laparoscopic antecolic antegastric linear divided as well as open retrogastric transmesocolic linear non-divided) were included. We aimed to create a stomach pouch of approximately $15-30 \mathrm{~mL}$ and a Roux-limb of 100-150cM.

Baseline features were listed: gender, age, preoperative weight, Body Mass Index (BMI), excess weight (EW), preoperative duration of diabetes, glycemic parameters (fasting glucose, $\mathrm{HbA} 1 \mathrm{c}$ ) and anti-diabetic therapy (insulin dependency). Standard surgical follow-up consisted of visits at 5 weeks, 10 weeks, 6 months and 1 year after surgery. Ideal weight, in order to calculate EW and \% Excess Weight Loss (\%EWL), was determined by recalculating individual lengths to a $\mathrm{BMI}$ of $25 \mathrm{~kg} / \mathrm{m}^{2}$.

Patients were divided into 2 groups according to their preoperative need for insulin: dependent (ID group) or independent. Insulin-independent patients were further subdivided into 2 groups: oral anti-diabetic medication (OAD) versus dietary and/or lifestyle management.

Postoperative biochemical analysis was carried out by an endocrinologist (in strict cooperation with the general practitioner) with regular visits depending on the 
Mid-term effect of Roux-en-Y gastric bypass on type 2 diabetes mellitus: a retrospective single surgeon observational study with focus on anti-diabetic medication

Gys, B; et al

type of anti-diabetic medication (insulin dependent patients were suggested a more vigilant follow-up). In addition, a subdivision was made according to diabetic response over time: "remission" and "non-remission" (including "improvement", "aggravation" or "status-quo" (SQ)). Emphasis was put on the need for medication compared with baseline needs.

"Remission" of diabetes was defined as a fasting glucose of less than $126 \mathrm{mg} / \mathrm{dl}$ and $\mathrm{HbA} 1 \mathrm{c}$ of less than $6.5 \%$ without the need of anti-diabetic medication for at least 6 months. "Improvement" was defined as a reduced need for anti-diabetic medication compared with baseline needs, "aggravation" as a higher need and "status quo" as unchanged. Finally "relapse" was defined as a renewed need for medication after initial "remission" was achieved.

Interpretation of continuous data was performed using the F-test. Because some patients did not have their weights documented at each determined interval, lacking data was interpolated by replacing missing values with estimates generated using application of polynomial spline function. To obtain maximum significance, no spatial interpolation concerning diabetic evolution or glycemic parameters (fasting glucose, $\mathrm{HbA1c}$ ) was used, only absolute data obtained from predetermined follow-up visits. Telephonic interviews were conducted to maximize mid-term follow-up data.

\section{RESULTS}

A total of 140 patients ( 97 women and 43 men) were included in our database (table 1). All patients were older than 18 years old and formed an absolute indication for bariatric surgery: $\mathrm{BMI}>40 \mathrm{~kg} / \mathrm{m}^{2}$ or BMl $>35 \mathrm{~kg} / \mathrm{m}^{2}$ with one or more comorbidities (refractory arterial hypertension, t2DM and/or proven sleep apnea). Mean age at surgery was 50 years old (range 19 - 69). Mean baseline BMI was $42.8 \mathrm{~kg} / \mathrm{m}^{2}$ (range 35.0 - 75.0) with a mean EW of $49.5 \mathrm{~kg}$ (range 19.3 - 119.2). The average disease duration prior to surgery was 5.7 years (range $0.0-30.1$ ). Preoperative need for antidiabetic medication was seen in 102 patients $(72.8 \%)$ of which $49(48.0 \%)$ were insulin dependent (ID group). 20 patients were newly diagnosed with type 2 diabetes during preoperative screening. In 18 patients, type 2 diabetes was managed without any use of medication (dietary and/or lifestyle management). 
Mid-term effect of Roux-en-Y gastric bypass on type 2 diabetes mellitus: a retrospective single surgeon observational study with focus on anti-diabetic medication

Gys, B; et al

Table 1: baseline subject characteristics.

mean value \pm standard deviation (range)

\begin{tabular}{lc}
\hline $\mathrm{n}$ & 140 \\
age (years) & $50 \pm 11(19-69)$ \\
female/male & $97 / 43$ \\
disease duration (years) & $5.7 \pm 7.0(0-30)$ \\
$\mathrm{BMI}^{*}\left(\mathrm{~kg} / \mathrm{m}^{2}\right)$ & $42.8 \pm 7.4(35.0-75.0)$ \\
$\mathrm{EW}^{* *}(\mathrm{~kg})$ & $49.5 \pm 20.2(19.3-119.2)$ \\
$\mathrm{HbA} 1 \mathrm{c}+(\%)$ & $7.3 \pm 1.3(5.3-12.3)$ \\
fasting glucose (mg/dl) & $156.0 \pm 60.0(46.0-200.0)$ \\
baseline management: & \\
$\quad$ insulin dependent: $\mathrm{n}(\%)$ & $49(35 \%)$ \\
$\quad$ insuline independent: $\mathrm{n}(\%)$ & $91(65 \%)$ \\
\hline${ }^{*} \mathrm{BMI}=$ Body Mass Index & \\
${ }^{* *} \mathrm{EW}=$ Excess Weight & \\
+HbA1c=Hemoglobine A1c &
\end{tabular}

Open retrogastric transmesocolic linear non-divided RYGB was performed in 33 patients, all others underwent standard 5-port trocar laparoscopy (antecolic antegastric linear divided). No postoperative mortality was encountered. Mean followup was 5.9 years (range 0.1 - 14.5). During follow-up, 3 patients died from nonesurgical related causes. One other patient was excluded during follow-up because of a pancreatectomy 4.5 year after RYGB.

Overall patient follow-up data was moderate with a lost-in-follow-up (LIFU) ratio of $22.5 \%$ after 1 year, $30.9 \%$ after 3 years, 39.2\% after 6 years and $42.9 \%$ after 10 years. Detailed attrition rate is illustrated in table 2 .

Postoperative weight loss was determined at each interval: 77.4\%EWL after 1 year, $69.7 \% \mathrm{EWL}$ after 3 years, $76.4 \% \mathrm{EWL}$ after 6 years and $55.9 \% \mathrm{EWL}$ after 10 years. There was no significant difference in weight loss (BMI, \%EWL) or mean fasting blood sugar between patients who experienced remission of diabetes and those who did not. In patients with remission, a significantly lower $\mathrm{HbA1c}$ was reported at 6 and 10 years after surgery $(P<0.05)$. Complete stratified postoperative results are illustrated in table 3. 
Mid-term effect of Roux-en-Y gastric bypass on type 2 diabetes mellitus: a retrospective single surgeon observational study with focus on anti-diabetic medication

Gys, B; et al

Table 2: attrition

\begin{tabular}{lcccc}
\hline years after surgery & ideal $(\mathrm{n})$ & actual $(\mathrm{n})$ & follow-up (\%) & LIFU* $(\%)$ \\
\hline baseline & 140 & 140 & 100.0 & 0.0 \\
$<1$ & 138 & 107 & 77.5 & 22.5 \\
$<3$ & 94 & 65 & 69.1 & 30.9 \\
$<6$ & 79 & 48 & 60.8 & 39.2 \\
$<10$ & 49 & 28 & 57.1 & 42.9 \\
\hline
\end{tabular}

*LIFU: Lost In Follow-Up

Table 3: stratified postoperative results

\begin{tabular}{lcccc}
\hline \multicolumn{1}{c}{ Variable } & overall & $\begin{array}{c}\text { t2DM } \\
\text { remission }\end{array}$ & $\begin{array}{c}\text { t2DM } \pm \text { non- } \\
\text { remission }\end{array}$ & p-value \\
\hline $\begin{array}{l}\text { \%EWL } \\
\text { 1yr }\end{array}$ & $77.4 \pm 19.3$ & $83.3 \pm 18.0$ & $76.7 \pm 19.5$ & 0.231 \\
3yrs & $69.7 \pm 26.7$ & $64.3 \pm 16.9$ & $78.2 \pm 24.9$ & 0.203 \\
6yrs & $76.4 \pm 25.7$ & $73.0 \pm 28.0$ & $79.7 \pm 27.0$ & 0.743 \\
10yrs & $55.9 \pm 31.1$ & $42.8 \pm 20.0$ & $62.4 \pm 35.1$ & 0.409 \\
\hline BMI** $\left(\mathrm{kg} / \mathrm{m}^{2}\right)$ & & & & \\
1yr & $29.4 \pm 4.6$ & $28.9 \pm 4.5$ & $29.6 \pm 4.7$ & 0.716 \\
3yrs & $30.9 \pm 5.7$ & $29.8 \pm 6.4$ & $31.6 \pm 2.3$ & 0.444 \\
6yrs & $26.2 \pm 7.0$ & $32.5 \pm 9.1$ & $27.8 \pm 3.9$ & 0.383 \\
10yrs & $33.9 \pm 2.4$ & $33.9 \pm 2.7$ & $30.1 \pm 5.2$ & 0.198 \\
\hline HbA1c† $\%)$ & & & & \\
1yr & $6.6 \pm 1.0$ & $5.8 \pm 0.7$ & $6.7 \pm 1.1$ & 0.156 \\
3yrs & $7.0 \pm 1.1$ & $6.0 \pm 0.9$ & $7.3 \pm 1.1$ & 0.059 \\
6yrs & $6.9 \pm 1.1$ & $6.2 \pm 0.4$ & $7.2 \pm 1.0$ & 0.002 \\
10yrs & $6.9 \pm 1.1$ & $5.9 \pm 0.5$ & $7.3 \pm 1.2$ & 0.043 \\
\hline fasting glucose $(\mathrm{mg} / \mathrm{dl})$ & & & & \\
1yr & $106.6 \pm 30.4$ & $91.0 \pm 22.4$ & $107.8 \pm 34.4$ & 0.601 \\
3yrs & $111.4 \pm 34.0$ & $108.5 \pm 24.2$ & $113.8 \pm 40.9$ & 0.581 \\
6yrs & $112.5 \pm 35.1$ & $107.2 \pm 18.1$ & $115.5 \pm 41.9$ & 0.417 \\
10yrs & $104.1 \pm 30.9$ & $102.7 \pm 11.0$ & $105.2 \pm 41.3$ & 0.850 \\
\hline
\end{tabular}

*\%WL $=$ percentage Excess Weight Loss

${ }^{* *} \mathrm{BMI}=$ Body Mass Index

$\dagger \mathrm{HbA} 1 \mathrm{c}=$ Hemoglobine $\mathrm{A} 1 \mathrm{c}$

‡t2DM = Type 2 Diabetes Mellitus 
Mid-term effect of Roux-en-Y gastric bypass on type 2 diabetes mellitus: a retrospective single surgeon observational study with focus on anti-diabetic medication

Gys, B; et al

Both groups (insulin dependent and independent patients) were compared with diabetic response (table 2). Remission was seen in $46.7 \%, 48.1 \%, 45.0 \%$ and $50.0 \%$ (insulin dependent patients) and in 59.1\%, 62.2\%, 53.3\% and $33.3 \%$ (insulinindependent patients) at respectively 1, 3, 6 and 10 years after surgery. No significant correlation was found between remission and the preoperative need for medication (insulin dependent versus independent patients), age, preoperative BMI or EW, preoperative $\mathrm{HbA} 1 \mathrm{c}$ or fasting glucose, disease duration or gender. Mean time until remission of diabetes was 4.6 years (range $0.4-12.7$ ) after surgery. A total of 6 patients experienced relapse after an average of 6.6 years (range 3.8 -13.2). Detailed diabetic response over time is displayed in table 4.

Table 4: stratified diabetic response over time

\begin{tabular}{|c|c|c|c|c|}
\hline \multirow{2}{*}{ Stratified diabetic } & \multicolumn{4}{|c|}{ Time } \\
\hline & 1 year & 3 years & 6 years & 10 years \\
\hline \multicolumn{5}{|l|}{ insulin dependent } \\
\hline $\mathrm{SQ}^{*}$ & $34.6 \%$ & $32.6 \%$ & $31.8 \%$ & $9.8 \%$ \\
\hline aggravation** & $3.3 \%$ & $7.4 \%$ & $5.0 \%$ & $8.3 \%$ \\
\hline improvement $†$ & $15.4 \%$ & $11.9 \%$ & $18.2 \%$ & $31.8 \%$ \\
\hline remission $\ddagger$ & $46.7 \%$ & $48.1 \%$ & $45.0 \%$ & $50.0 \%$ \\
\hline \multicolumn{5}{|l|}{ insulin independent } \\
\hline$S Q^{*}$ & $26.7 \%$ & $29.9 \%$ & $32.3 \%$ & $48.0 \%$ \\
\hline aggravation** & $6.7 \%$ & $7.9 \%$ & $9.7 \%$ & $16.0 \%$ \\
\hline improvement † & $7.6 \%$ & $0.0 \%$ & $4.7 \%$ & $2.7 \%$ \\
\hline remission $\ddagger$ & $59.1 \%$ & $62.2 \%$ & $53.3 \%$ & $33.3 \%$ \\
\hline
\end{tabular}

\section{DISCUSSION}

The various mechanisms and their individual potential in which RYGB positively influences type 2 diabetes are still under investigation ${ }^{5} 6$. Improvement of glucose homeostasis after RYGB is frequently seen even before significant weight loss is achieved ${ }^{7}$. It is believed that a complex alteration in gut hormones is responsible for this phenomenon ${ }^{8} 910$ and therefore like it is showed in this study, remission of diabetes is not always significantly correlated with weight loss ${ }^{11} 12$. 
Mid-term effect of Roux-en-Y gastric bypass on type 2 diabetes mellitus: a retrospective single surgeon observational study with focus on anti-diabetic medication

Gys, B; et al

Our retrospective data analysis show a mid-term beneficial response of t2DM after RYGB in the majority of patients with an overall remission rate of $52.9 \%$ after 1 year, $55.1 \%$ after 3 years, $49.1 \%$ after 6 years and $41.7 \%$ after 10 years. Our results are slightly lower than other studies ranging from $26-100 \%$ after 1 year, $81 \%$ after 3 years, $44-88 \%$ after 5 years and $71-89 \%$ after 10 years ${ }^{13141516}$. Attrition bias and variable definitions of "remission" in literature might be among the possible explanations for the variety in these numbers. Also, the majority of all cited studies is based on retrospective analysis with at least moderate lost-in-follow-up ratios, especially on mid-term base.

No significant correlation was found between diabetes remission and gender, preoperative duration of t2DM, baseline age, BMI, Hba1c or fasting glucose. Some studies however, did show significant correlation, especially for baseline $\mathrm{HbA1c}$, age, preoperative use of insulin and/or disease duration ${ }^{17}{ }^{18}$. Unfortunately, relapse of t2DM was present in 13.3\%. Similar population-based studies showed relapses of 24.0 $43.1 \%$ correlated with female sex, early disease stage at the moment of surgery and/or a lower baseline $\mathrm{BMI}^{19} 20$.

Bariatric surgery is useful in the mid-term management of uncontrolled t2DM in patients who are insulin dependent and those who are not. Relapse was observed in some patients and therefore we should be critical about mid-term durability. In literature, "remission" of t2DM can vary depending on the criteria ${ }^{21}$. We chose to focus on the use of medication rather than on biochemical parameters. In order to establish the real potential effects and their significance, more (prospective) analysis is necessary. In conclusion, bariatric surgery is useful in the mid-term management of uncontrolled t2DM.

\section{Acknowledgments}

We would like to thank Matisse Raeymaekers for endless support.

\section{REFERENCES}

1. WHO. Global status report on noncommunicable diseases 2014. World Health Organization, Geneva; 2014. 
Mid-term effect of Roux-en-Y gastric bypass on type 2 diabetes mellitus: a retrospective single surgeon observational study with focus on anti-diabetic medication

Gys, B; et al

2. WHO. Global health estimates: deaths by cause, age, sex and country, 2000-2012. World Health Organization, Geneva; 2014.

3. World Health Organization (2013) Diabetes Fact sheet №312. http://www.who. int/mediacentre/factsheets/fs312/en

4. WHO. Definition and Diagnosis of Diabetes Mellitus and Intermediate Hyperglycemia. Geneva: World Health Organization; 2006. pp. 1-46. Report of a WHO/IDF Consultation.

5. Cummings $\mathrm{DE}$, Foster-Schubert $\mathrm{KE}$, Carlson $\mathrm{MJ}$,et al. Possible hormonal mechanisms mediating the effects of bariatric surgery. In: Pitombo C (ed). Obesity Surgery: Principle and Practice. McGraw-Hill: New York, 2007, pp 137-147.

6. Rubino F, R'bibo SL, del Genio F, et al. Metabolic surgery: the role of the gastrointestinal tract in diabetes mellitus. Nat Rev Endocrinol. 2010;6:102-9.

7. Dirksen C, Jørgensen NB, Bojsen-Møller KN, et al. Mechanisms of improved glycaemic control after Roux-en-Y gastric bypass. Diabetologia. 2012;55(7):1890-901.

8. Scott WR, Batterham RL. Roux-en-Y gastric bypass and laparoscopic sleeve gastrectomy: understanding weight loss and improvements in type 2 diabetes after bariatric surgery. Am J Physiol Regul Integr Comp Physiol. 2011;301(1):R15-27.

9. Allison B. Patti G, Patti ME. Diabetes improvement following roux-en-y gastric bypass: understanding dynamic changes in insulin secretion and action. Diabetes 2014;63:1454-145.

10. Bojsen-Møller KN. Mechanisms of improved glycaemic control after roux-en-y gastric bypass. Dan Med J. 2015;62(4):B5057.

11. Pournaras DJ, Osborne A, Hawkins SC, et al. Remission of type 2 diabetes after gastric bypass and banding: mechanisms and 2 year outcomes. Ann Surg. 2010 ;252(6):966-71.

12. Cohen RV, Pinheiro JC, Schiavon CA. Effects of gastric bypass surgery in patients with type 2 diabetes and only mild obesity. Diabetes Care. $2012 ; 35(7): 1420-8$.

13. Lacobellis G, Xu C, Campo RE, et al. Predictors of short-term diabetes remission after laparoscopic roux-en-y gastric bypass. Obes Surg. 2015;25(5):782-7.

14. Yip S, Plank LD, Murphy R. Gastric bypass and sleeve gastrectomy for type 2 diabetes: a systematic review and meta-analysis of outcomes. Obes Surg. 2013 ;23(12):1994-2003.

15. Davies SW, Efird JT, Guidry CA, et al. Long-term diabetic response to gastric bypass. J Surg Res. 2014;190(2):498-503. 
16. Kadera BE, Lum K, Grant J, et al. Remission of type 2 diabetes after roux-en-y gastric bypass is associated with greater weight loss. Surg Obes Relat Dis. 2009 ;5(3):305-9.

17. Dicker D, Yahalom R, Comaneshter DS, et al. Long-term outcomes of three types of bariatric surgery on obesity and type 2 diabetes control and remission. Obes Surg. 2016;26(8):1814-20.

18. Park JY, Kim YJ. Prediction of diabetes remission in morbidly obese patients after roux-en-y gastric bypass. Obes Surg. 2016;26(4):749-56.

19. DiGiorgi M, Rosen DJ, Choi JJ, et al. Re-emergence of diabetes after gastric bypass in patients with mid- to long-term follow-up. Surg Obes Relat Dis. 2010 ;6(3):249-53.

20. Chikunguwo SM, Wolfe LG, Dodson P, et al. Analysis of factors associated with durable remission of diabetes after Roux-en-Y gastric bypass. Surg Obes Relat Dis. 2010;6(3):254-9.

21. Rodríguez-Ortiz D, Reyes-Pérez A, León $P$, et al. Assessment of two different diagnostic guidelines criteria (National Cholesterol Education Adult Treatment Panel III [ATP III] and International Diabetes Federation [IDF]) for the evaluation of metabolic syndrome remission in a longitudinal cohort of patients undergoing Roux-en-Y gastric bypass. Surgery. 2016;159(4):1121-8. 